\title{
Rapid de novo aneurysm formation after clipping of a ruptured middle cerebral artery aneurysm in an infant with an MYH11 mutation
}

\author{
Vijay M. Ravindra, MD, MSPH, ${ }^{1}$ Michael Karsy, MD, PhD, ${ }^{1}$ Richard H. Schmidt, MD, PhD, ${ }^{1}$ \\ Philipp Taussky, MD, ${ }^{1}$ Min S. Park, MD, ${ }^{1}$ and Robert J. Bollo, MD ${ }^{1,2}$ \\ 1Department of Neurosurgery, Clinical Neurosciences Center, University of Utah; and 2Division of Pediatric Neurosurgery, \\ Primary Children's Hospital, University of Utah, Salt Lake City, Utah
}

\begin{abstract}
The authors report the case of a previously healthy 6-month-old girl who presented with right arm and leg stiffening consistent with seizure activity. An initial CT scan of the head demonstrated acute subarachnoid hemorrhage in the basal cisterns extending into the left sylvian fissure. Computed tomography angiography demonstrated a $7 \times 6 \times 5-\mathrm{mm}$ saccular aneurysm of the inferior $\mathrm{M}_{2}$ division of the left middle cerebral artery. The patient underwent left craniotomy and microsurgical clip ligation with wrapping of the aneurysm neck because the vessel appeared circumferentially dysplastic in the region of the aneurysm. Postoperative angiography demonstrated a small remnant, sluggish distal flow, but no significant cerebral vasospasm. Fifty-five days after the initial aneurysm rupture, the patient presented again with an acute intraparenchymal hemorrhage of the left anterior temporal lobe. Angiogram revealed a circumferentially dysplastic superior division of the $\mathrm{M}_{2}$ branch, with a new $5 \times 4-\mathrm{mm}$ saccular aneurysm distinct from the first, with 2 smaller aneurysms distal to the new ruptured aneurysm. Endovascular parent vessel occlusion with Onyx was performed. Genetic testing revealed a mutation of the MYH11. To the authors' knowledge, this is the first report of rapid de novo aneurysm formation in an infant with an MYH11 mutation. The authors review the patient's clinical presentation and management and comprehensively review the literature on this topic.
\end{abstract}

http://thejns.org/doi/abs/10.3171/2016.5.PEDS16115

KEY WORDS saccular aneurysm; muslin gauze; angiogram; pediatric; myosin heavy chain 11; MYH11; vascular disorders

$\mathrm{A}$ NEURYSMAL subarachnoid hemorrhage ( $\mathrm{SAH}$ ) is a significant cause of morbidity and mortality. The estimated incidence of SAH is 5-10 cases per 100,000 patients per year. ${ }^{34}$ Children account for $0.5 \%-$ $4.6 \%$ of all patients with aneurysms in large published series. $5,7,19,21,24,28,32$ Aneurysms in the first 2 decades of life account for $1 \%-4 \%$ of all intracranial aneurysms. . $^{12,15,17,29}$ As in adults, the treatment of intracranial aneurysms in children can involve microsurgical clip ligation, wrapping, and endovascular treatment including flow diversion, coiling, and embolization of the aneurysm and parent vessel. , $13,14,20,30,34,37$ The rate of new SAH is higher in both adults and children with a previous aneurysm rupture than in the general population; it occurs as a result of re- current aneurysms as well as de novo aneurysm formation. ${ }^{4,35,39}$ In pediatric patients with a mean follow-up of 4-6 years, ${ }^{11,15,30}$ a $13 \%-23 \%$ cumulative rate of de novo aneurysm formation has been reported..$^{15,29,30}$

We discuss the case of a 6-month-old girl who initially presented with a ruptured left middle cerebral artery (MCA) aneurysm treated with microsurgical clip ligation who had de novo aneurysm formation and rupture from an adjacent segment just 55 days later and was found to have a mutation in the myosin heavy chain 11 , smooth muscle gene (MYH11). We present the imaging and clinical course of this case and review the literature on recurrent spontaneous aneurysm formation and rupture in the pediatric population.

ABBREVIATIONS CTA = CT angiography; EVD = external ventricular drain; ICU = intensive care unit; $M C A=$ middle cerebral artery; $M R A=M R$ angiography; SAH = subarachnoid hemorrhage; TAAD = thoracic aortic aneurysm and dissection.

SUBMITTED February 25, 2016. ACCEPTED May 9, 2016.

INCLUDE WHEN CITING Published online July 1, 2016; DOI: 10.3171/2016.5.PEDS16115. 


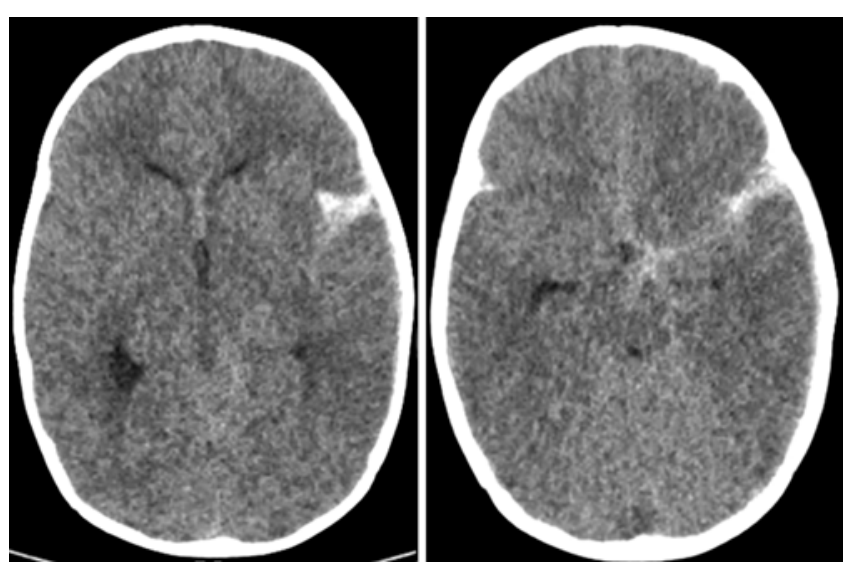

FIG. 1. Axial noncontrast head CT demonstrating a focus of SAH along the left sylvian fissure (left) with blood extending along the circle of Willis. Left temporal lobe edema with dilation of the right temporal horn indicating obstructive hydrocephalus (right).

\section{Case Report}

Initial Presentation

A 6-month-old female with no significant medical history presented to an outside emergency department with a new-onset focal seizure consisting of tonic posturing of the right upper and right lower extremities. Intravenous levetiracetam was administered, and a noncontrast head CT scan demonstrated an SAH centered along the left sylvian fissure with blood extending around the circle of Willis, hypodensity within the left MCA territory, and an acute, thin left subdural hematoma (Fig. 1).

The patient was transferred via air ambulance to our institution for neurosurgical evaluation and management. On arrival, she was bradycardic and hypertensive. Her anterior fontanelle was full but not tense, and there were no signs of external trauma. Her pupillary examination demonstrated asymmetry; the left pupil was minimally reactive and the right pupil was briskly reactive. Her motor examination demonstrated withdrawal in the left upper and lower extremities with no observable movement in the right upper and lower extremities upon stimulation. Computed tomography angiography (CTA) demonstrated a $7 \times 6 \times 5-m m$ saccular aneurysm of the left MCA inferior division of the $\mathrm{M}_{2}$ segment (Fig. 2). The patient was admitted to the intensive care unit (ICU), treated with hypertonic saline, and hemodynamically stabilized with strict blood pressure control. She had no family history of bleeding disorders, cerebral aneurysms, or inherited vasculopathy, connective tissue disease, or history of congenital heart disease.

\section{Initial Surgical Management}

A multidisciplinary decision was made to treat the ruptured aneurysm via microsurgical clip ligation given the patient's young age, the aneurysm location at the MCA bifurcation, and the technically challenging morphology from an endovascular perspective. A formal angiogram was not obtained because the aneurysm geometry and parent vessel anatomy were well visualized by the CTA, and we did not want to expose the infant to additional diagnos-
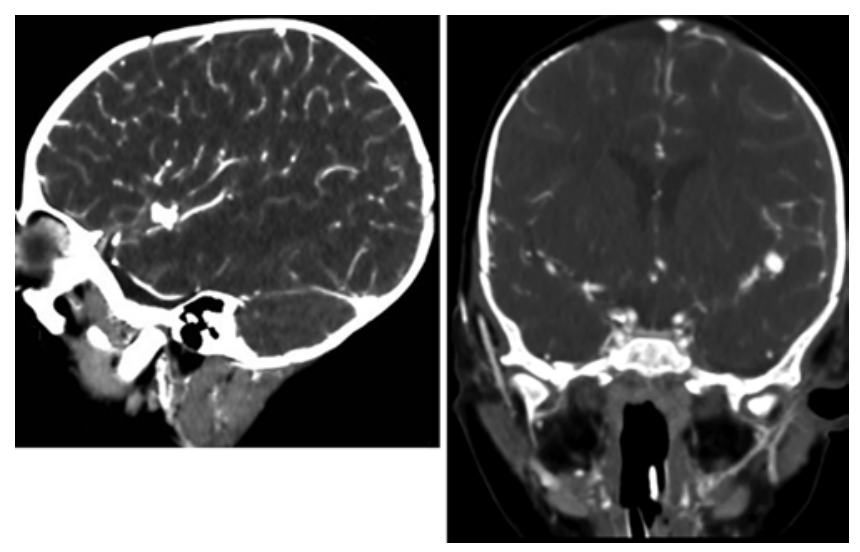

FIG. 2. Sagittal (left) and coronal (right) CT angiograms demonstrating a left MCA aneurysm along the $\mathrm{M}_{2}$ segment. The aneurysm measures 7 $\times 6 \times 5 \mathrm{~mm}$ and arises from the inferior division of the $\mathrm{M}_{2}$ bifurcation.

tic radiation that would not affect our treatment decision. The patient underwent a left frontotemporal craniotomy and placement of an external ventricular drain (EVD), and the aneurysm was secured with clips after transsylvian dissection of the MCA bifurcation and aneurysm.

Intraoperatively, we initially encountered the subdural hematoma; after evacuation, we noted that the pia along the sylvian fissure was torn parallel to the fissure, communicating the subarachnoid space and acute aneurysmal hemorrhage with the subdural space. After extending this opening and evacuating the hemorrhage within the sylvian fissure, we visualized the aneurysm, and the $\mathrm{M}_{1}$ segment was dissected. A temporary clip was placed across the $\mathbf{M}_{1}$ trunk, and the vessel was followed to the aneurysm's neck along the inferior $\mathrm{M}_{2}$ branch, which appeared circumferentially dysplastic. A large straight titanium clip was initially placed across the aneurysm neck, but micro-Doppler ultrasonography demonstrated no distal flow. The clip was repositioned with restoration of flow, leaving a small bleb of the aneurysm outside the clip. A small curved clip was stacked beneath the straight clip. Because the entire parent vessel appeared dysplastic, it was circumferentially wrapped with muslin gauze. Micro-Doppler ultrasonography demonstrated good distal flow after temporary clip removal.

\section{Initial Postoperative Course}

The patient was managed in the pediatric ICU postoperatively. A head CT on postoperative Day 1 (Fig. 3) demonstrated an intact clip construct and decompression of the ventricles with the EVD. She underwent cerebral angiography on postoperative Day 5 (postictus Day 6), which visualized the clip construct (Fig. 4A). Anterior projections (Fig. 4B and C) demonstrated obliteration of the aneurysm, as well as a small bleb remnant. There was some evidence of delayed filling of the distal $\mathrm{M}_{2}$ vessels on the left side but no definitive evidence of vasospasm; it probably represented partial occlusion of the vessel distal to the aneurysm clip. Given the patient's improving clinical examination findings, she was monitored with no intervention. The remainder of the cerebrovasculature appeared normal, without evidence of vasculitis or addition- 


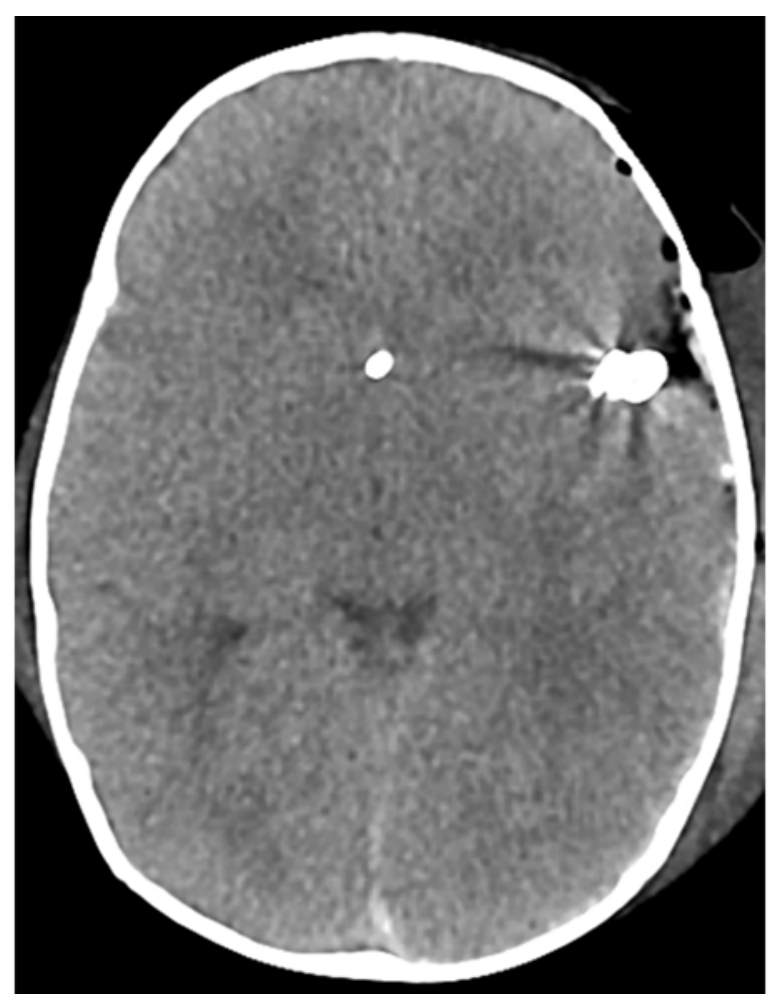

FIG. 3. Postoperative noncontrast head CT scan demonstrating a left frontal ventriculostomy catheter with decompression of the ventricles. The clip construct is visible on the left side. There is diffuse cerebral edema of the left temporal lobe.

al aneurysm. Magnetic resonance imaging demonstrated evidence of diffusion restriction along the posterior temporal lobe with associated encephalomalacia, compatible with infarction (Fig. 5).

The patient continued to experience seizures in the postoperative period and was monitored with continuous video electroencephalography. Phenobarbital was administered in addition to the levetiracetam, and her seizures resolved. She was weaned from the EVD, which was clamped and eventually removed without hydrocephalus. She was treated with nimodipine $(0.75 \mathrm{mg} / \mathrm{kg}$ every 4
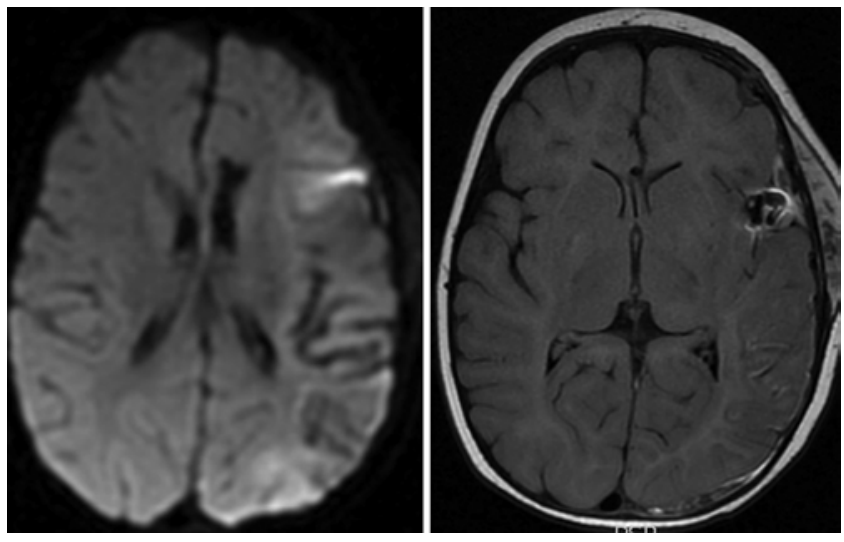

FIG. 5. Magnetic resonance images demonstrating diffusion restriction along the posterior temporal lobe with associated encephalomalacia (left) and T1 shortening (right) compatible with a previous stroke in this distribution.

hours) postoperatively for 17 days without adverse effects. She was transferred from the pediatric ICU after 12 days, weaned from levetiracetam, and discharged 20 days after admission with improving right hemiparesis.

\section{Second Presentation}

Fifty-five days after the initial aneurysm rupture, the patient developed recurrent seizure activity with clonic movement of the right upper and lower extremities. Computed tomography scanning of the head without contrast demonstrated a new, acute intraparenchymal hemorrhage of the left anterior temporal lobe into the area of previous ischemia (Fig. 6), without significant mass effect. After the reintroduction of levetiracetam, the patient rapidly returned to her baseline except for a worsening of her right hemiparesis. Computed tomography angiography demonstrated a de novo saccular aneurysm measuring $5 \times 4 \mathrm{~mm}$ along the superior $\mathrm{M}_{2}$ branch of the left MCA (Fig. 7), representing a de novo ruptured aneurysm.

\section{Second Surgical Management and Hospital Course}

The patient was once again stabilized in the pediatric ICU, and the next day a cerebral angiogram confirmed de

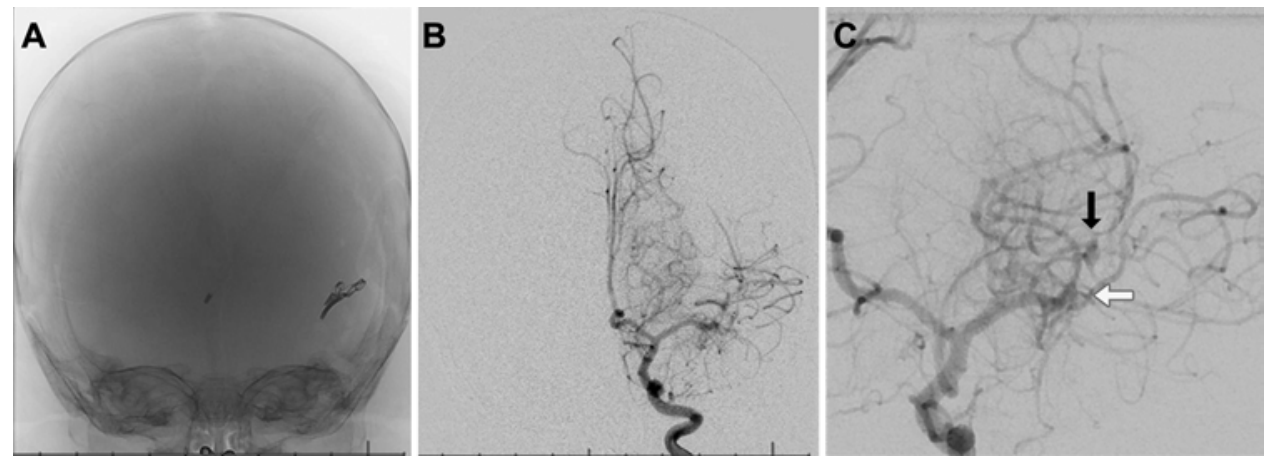

FIG. 4. Digital subtraction angiography obtained on postoperative Day 5 (posthemorrhage Day 6). Anterior skull projection (A) demonstrating the clip construct. Anterior projection (B) demonstrating filling of the distal MCA vessels, and a magnified anterior projection $(\mathbf{C})$ demonstrating obliteration of the aneurysm, as well as a small bleb remnant (black arrow). There was some evidence of delayed filling of the distal $\mathrm{M}_{2}$ vessels on the left side but no florid evidence of vasospasm. Note that the distal vasculature appears intact with no evidence of irregularity (white arrow). 


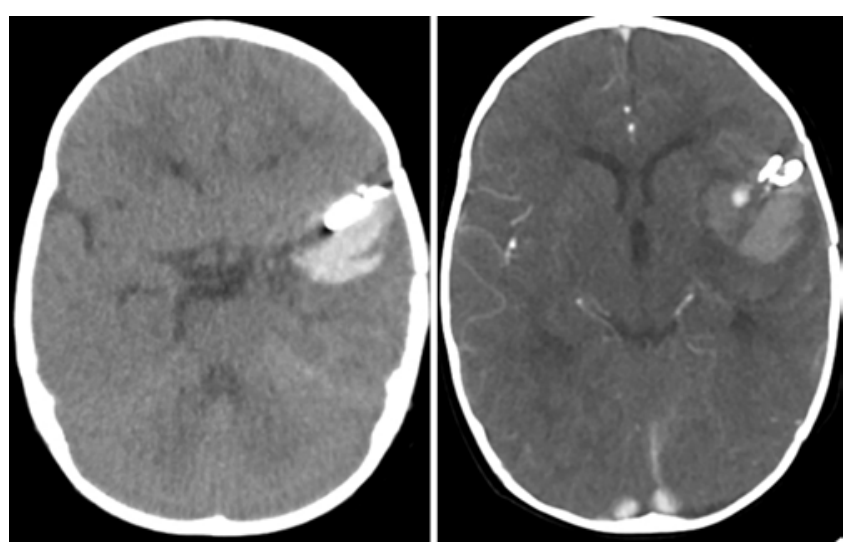

FIG. 6. Noncontrast head CT scans obtained at the second presentation, demonstrating an intraparenchymal hemorrhage of the left anterior temporal lobe.

novo aneurysm formation on a different $\mathrm{M}_{2}$ branch from the initial aneurysm, as well as dysplastic features of the vessel distal to the aneurysm, with 2 additional smaller aneurysms forming (Fig. 8A). In the context of prior stroke and the short interval between initial aneurysm rupture and de novo aneurysm formation with dysplastic features distal to the de novo lesion, the decision was made to sacrifice the parent vessel, which was successfully achieved with Onyx embolization (Fig. 8). The patient underwent MRI of the brain the following day, which demonstrated a stable appearance of the hematoma, evolution of the previous stroke, and no new restricted diffusion within the left MCA territory (Fig. 9). She had an uneventful postoperative course and was discharged home 4 days later with an improving right hemiparesis.

\section{Medical Evaluation}

Serological testing did not support a diagnosis of vasculitis (erythrocyte sedimentation rate [ESR] 6, C-reactive protein [CRP] 0.6, antinuclear antibody [ANA] negative), the patient's von Willebrand factor level was normal, and myeloperoxidase and proteinase 3, anti-cardiolipin IgG/ IgM, and $\beta 2$ glycoprotein $\operatorname{IgG/IgM~tests~were~negative.~}$
Coagulation studies demonstrated a normal prothrombin time with slightly elevated partial thromboplastin time, which corrected with a 1:1 mixing study, and a negative lupus anticoagulant assay.

Genetic testing was performed using a 21-gene aortopathy vasculopathy panel array. This revealed a heterozygous mutation of $M Y H 11$ on $16 \mathrm{p} 13.11$ (c.5273G > A), which encodes the myosin heavy chain 11 protein in smooth muscle. Mutations in $\mathrm{MYH} 11$ have been associated with thoracic aortic aneurysms and dissections (TAADs) but never with cerebral aneurysms.

\section{Follow-Up}

Three months after her initial aneurysm rupture, the patient was seen in follow-up. She demonstrated additional improvement in her right hemiparesis, no further seizures, and no signs of hydrocephalus. Surveillance imaging with MR angiography (MRA) is planned to screen for new aneurysm formation.

\section{Discussion}

We present the case of a 6-month-old infant who initially presented with rupture from a left MCA inferior $\mathrm{M}_{2}$ branch aneurysm that was managed with microsurgical clip ligation; the patient returned just 55 days later with de novo aneurysm formation and rupture along the superior branch. This subsequent occurrence was treated with Onyx embolization of the aneurysm and the parent vessel. Genetic testing demonstrated that the patient is heterozygous for an MYH11 mutation. This is the first report of rapid de novo aneurysm formation in an infant with an MYH11 mutation.

\section{Epidemiology and Natural History}

Cerebral aneurysms in children account for $0.5 \%-$ $4.6 \%$ of those in large reported series of intracranial aneurysms, $5,1,19,21,24,28,32$ and lesions diagnosed in the first 2 decades of life account for $1 \%-4 \%$ of all intracranial aneurysms. ${ }^{12,15,17,29}$ Compared with those in adults, cerebral aneurysms in young children are more often nonsaccular, dissecting, or fusiform. ${ }^{8}$ Additionally, they are more com-
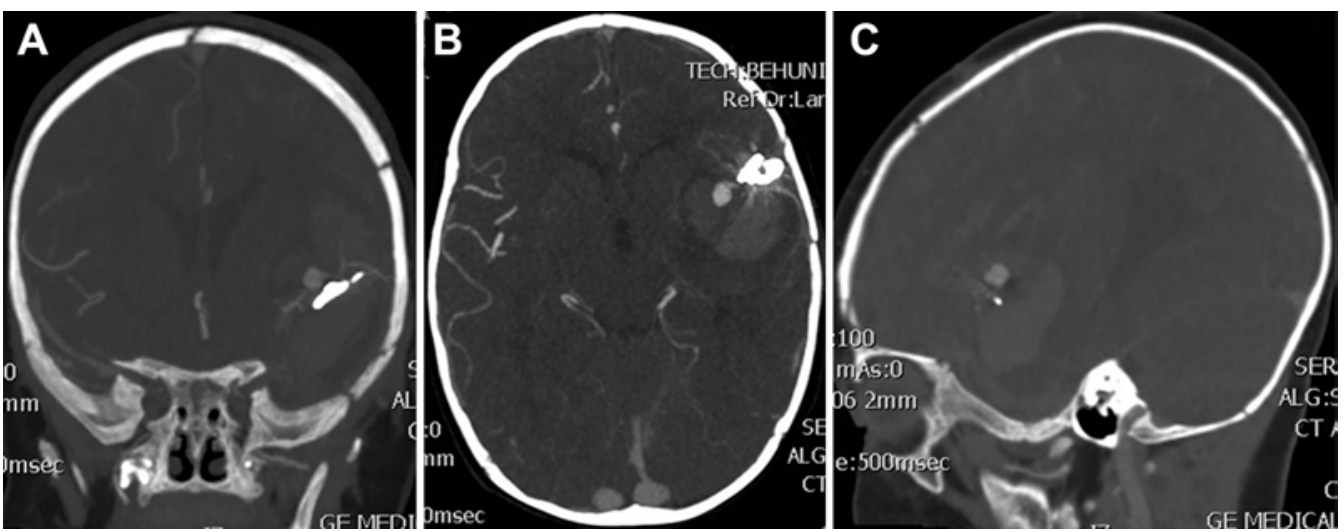

FIG. 7. Coronal (A), axial (B), and sagittal (C) CT angiograms with evidence of a de novo left MCA saccular aneurysm measuring $5 \times 4 \mathrm{~mm}$ along the superior division of the left $\mathrm{M}_{2}$ segment, a distinctly different origin and location of this aneurysm with respect to the initial aneurysm. 

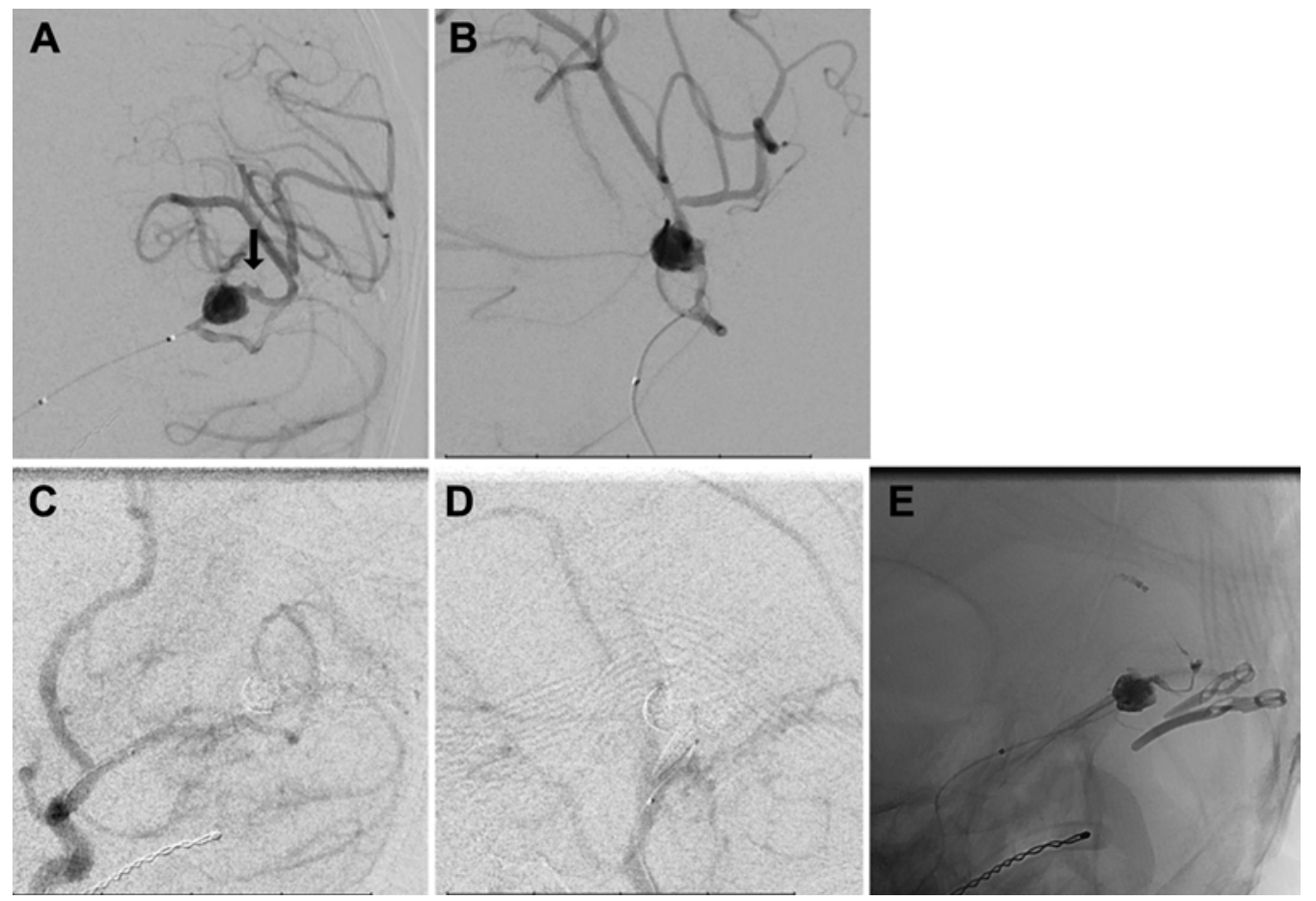

FIG. 8. Digital subtraction angiograms, anteroposterior (A) and lateral (B) projections, demonstrating dysplastic features of the vessel distal to the aneurysm (arrow). Post-embolization anteroposterior angiograms, left anterior oblique (C) and lateral (D) projections, demonstrating successful Onyx embolization of the aneurysm and parent vessel. The Onyx cast is visualized on the anterior projection of the skull $(\mathrm{E})$ and is away from the original clip construct, which is also visible.

monly secondary to systemic conditions including infection, inherited vasculopathy, familial connective tissue disease, and congenital heart disease. ${ }^{3}$ Pediatric cerebral aneurysms are also more frequently giant, tend to form in the posterior circulation and at the internal carotid artery bifurcation, and have a male preponderance..$^{19,26,30,33}$ Fusiform aneurysms are less common in adults, more common in children, ${ }^{6,11}$ and frequently occur along the MCA branches. ${ }^{6}$ The featured case represents a rare saccular aneurysm arising from the inferior division of $\mathrm{M}_{2}$ with de novo saccular aneurysm formation at the superior division of $\mathrm{M}_{2}$.

The rapid de novo aneurysm formation in the presented case is concerning but sheds light on cerebral aneurysms as a disease process rather than a single lesion that requires treatment. Despite a number of large series of pediatric cerebral aneurysms, a paucity of literature covers the timing of de novo aneurysm formation, particularly in infants. Stiefel and colleagues ${ }^{34}$ documented a series of 12 patients with 13 aneurysms over a 12-year period, including 1 patient with severe Takayasu's arteritis who developed a de novo ruptured aneurysm after 6 months, leading to her death. In contrast, our patient had no evidence of vasculopathy, a rheumatological condition, or a congenital disorder that would put her at risk for rapid formation and rupture of 2 cerebral aneurysms. In a series of 32 patients treated with both open surgical clipping and endovascular coiling, Sanai and colleagues ${ }^{30}$ reported on 4 pediatric patients (10-15 years old) with de novo aneurysms separated from initial treatment by 18-180 months, all much longer intervals than in our patient. Table 1 summarizes multiple large series of pediatric cerebral aneurysms and reports of de novo aneurysm formation timing.

\section{Myosin Heavy Chain 11}

Myosin heavy chain 11 protein is a specific contractile protein of smooth muscle cells. ${ }^{27}$ Mutations in MYH11 have been identified in 2 families with autosomal dominant inheritance leading to TAAD in conjunction with patent ductus arteriosus. ${ }^{40}$ The hypothesized mechanism is a disturbance in contractile smooth muscle cell function leading to lower aortic compliance and elastolysis with
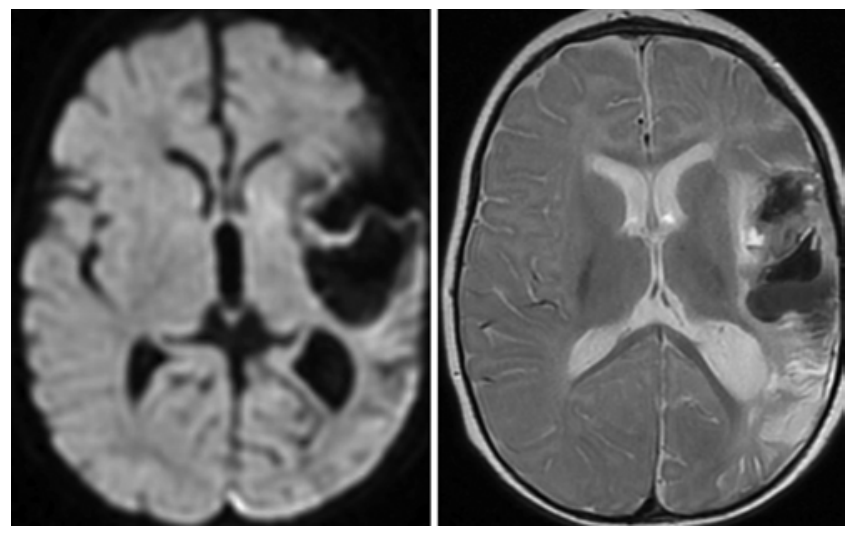

FIG. 9. Brain MR images obtained on postprocedure Day 1, demonstrating the hemorrhage and previous stroke with no evidence of a new ischemic insult to the vascular territory (left) and evidence of T2 elongation (right). 
TABLE 1. Summary of reports of pediatric cerebral aneurysms including some with de novo aneurysm formation

\begin{tabular}{|c|c|c|c|c|c|c|}
\hline Authors \& Year & $\begin{array}{c}\text { No. of } \\
\text { Patients }\end{array}$ & $\begin{array}{l}\text { Mean Age of } \\
\text { Patients in Yrs } \\
\text { (range) }\end{array}$ & $\begin{array}{c}\text { No. of } \\
\text { De Novo } \\
\text { Aneurysms }\end{array}$ & $\begin{array}{l}\text { Age (yrs) \& Sex of Patient } \\
\text { w/ Shortest Time to De } \\
\text { Novo Aneurysm Formation }\end{array}$ & $\begin{array}{l}\text { Shortest Time to } \\
\text { De Novo Aneurysm } \\
\text { Formation (mos) }\end{array}$ & Outcome \\
\hline Patel \& Richardson, 1971 & 58 & $15.5(8-19)$ & 0 & NA & NA & NA \\
\hline Ostergaard \& Voldby, 1983 & 43 & $14.7(1-19)$ & 0 & NA & NA & NA \\
\hline Proust et al., 2001 & 21 & $12.27(7-16)$ & 0 & NA & NA & NA \\
\hline Sanai et al., 2006 & 32 & $11.7(0.16-18)$ & 4 & $15, F$ & 18 & Weakness \\
\hline Stiefel et al., 2008 & 12 & $5.1(0.33-16)$ & 1 & $2.1, F$ & 6 & Death \\
\hline Saraf et al., 2012 & 23 & $13(0.16-18)$ & 0 & NA & NA & NA \\
\hline Current case & 1 & NA & 1 & $0.5, F$ & 2 & No new neurological deficit \\
\hline
\end{tabular}

NA = not applicable.

focal vascular smooth muscle hyperplasia. ${ }^{22}$ The identification and association of MYHII mutations with thoracic aortic aneurysms confirms the critical importance of the smooth muscle cell contractile system to maintain the structural integrity of the ascending aorta. ${ }^{9}$ Immunohistochemistry staining of aortic biopsy specimens from a patient and family member with an MYHII also demonstrated upregulation of the transforming growth factor $-\beta$ (TGF- $\beta$ ) signaling pathway. ${ }^{27}$

At the molecular level, patients with TAAD harbor the mutation identified in our patient, which leads to the amino acid alteration of p.Arg1758Gln, together with the IVS32+1G $>\mathrm{T}$ allelic variant. Together this mutation and variant results in an in-frame deletion and the loss of exon 32 encoding 71 amino acids. ${ }^{40}$ This causes a conformational change in the alpha-helical coiled-coil domain of the smooth muscle myosin heavy chain. That conformational change prevents the protein from assembling into a functional homodimer, leading to a dominant negative effect. ${ }^{40}$ Although our patient harbors the same mutation, the IVS32+1G $>$ T allelic variant was not found, so it is unclear if the mutation alone leads to a similar conformational change of the alpha-helical coiled-coil domain. However, the amino acid change caused by the mutation (p.Arg1758Gln) impacts a highly conserved arginine residue in the myosin heavy chain 11 protein, which strongly suggests this mutation may be pathogenic. ${ }^{2}$

Although MYHII mutations are associated with TAAD, an association with cerebral aneurysms has not been reported. The patient featured in this report represents an index case and may shed light on an important molecular pathway that leads to the formation of cerebral aneurysms in children. The mechanism is probably similar to the formation of thoracic aortic aneurysms - namely, progressive decrease in vessel wall compliance with elastolysis eventually leading to rupture.

An additional mutation in smooth muscle cytoskeletal protein actin alpha-2 (ACTA2), which has been associated with moyamoya disease and stroke, ${ }^{9}$ was not detected in this case.

\section{Long-Term Surveillance}

The long-term surveillance and management of children with cerebral aneurysms presents a distinct challenge. Koroknay-Pál and colleagues ${ }^{18}$ reported on the long-term follow-up (median 34 years, range 4-56 years) of a cohort of 59 children who presented with cerebral aneurysms between 1937 and 2009 in Finland. Based on 1935 personyears of follow-up, the annual rate of de novo or recurrent aneurysm formation was $1.9 \%$, with a $0.4 \%$ annual rate of hemorrhage. Among patients with a prior SAH (52 [88\%] of 59), during 1766 person-years of follow-up, the annual rate of de novo or recurrent aneurysm formation was $2.0 \%$, and the annual hemorrhage rate was $0.5 \%$. One-third of patients developed more than one new aneurysm, but the earliest symptomatic recurrent aneurysm occurred 6 years after treatment. Given these data, the authors recommended that all children diagnosed with intracranial aneurysms should undergo surveillance MRA at 3- to 5-year intervals. Our case suggests that the rate of early aneurysm formation and SAH may be higher and would warrant closer surveillance in this population, especially in the context of a likely pathological $M Y H 11$ mutation.

In a previous publication, the same investigators reported on 102 children with intracranial aneurysms. ${ }^{16}$ In that cohort, 80 patients (78\%) survived 1 year after SAH; among them, 8 patients (10\%) died of recurrent SAH after a median time of 11 years (range 1.5-33.4 years). The cause of recurrent SAH was de novo aneurysm rupture in 3 patients and recurrent rupture of an incompletely occluded aneurysm in 4 patients (1 patient was lost to follow-up). The investigators concluded that, over the long term, there are high rates of excess mortality due to recurrent aneurysms and hemorrhage in children who present with intracranial aneurysms. The case we present is unusual because of the rapid de novo aneurysm formation; therefore, the patient will require long-term radiographic surveillance. In addition to the known risk factors for aneurysm growth and rupture in adults - smoking, hypertension, and excessive alcohol use - the patient has a high risk of de novo aneurysm formation, intracranial hemorrhage, and neurological morbidity from progressive cerebrovascular disease. ${ }^{16}$

\section{Treatment}

The treatment options for cerebral aneurysms in children are similar to those used in adults, including microsurgical clip ligation and endovascular occlusion. Stiefel and colleagues $^{34}$ suggested that microsurgical clipping should be the standard first-line treatment for all aneurysms, except when surgery is not a viable option or for lesions at 
the basilar apex. Their report predates the widespread use of endovascular techniques including embolization and flow diversion, which are becoming more commonplace in the treatment of pediatric aneurysms. ${ }^{1,13,14,20,30,34,37}$

Specifically, liquid embolization, coil embolization, and flow diversion represent new frontiers in the treatment of pediatric cerebral aneurysms, and their use should be considered carefully. ${ }^{31}$ In the featured case, microsurgical clip ligation was used to treat the initial MCA aneurysm, which was not considered amenable to endovascular occlusion given its geometry, its MCA location, and the patient's age. ${ }^{36}$ The de novo aneurysm was embolized using Onyx liquid embolization (Covidien), and the parent vessel was sacrificed because of the dysplastic appearance of the distal vessel and the potential of future aneurysms to form along this segment (Fig. 8C). Onyx is routinely used as an off-label liquid embolic for vessel occlusions for persistent epistaxis, pseudoaneurysm occlusion, and tumor embolizations. Onyx offers the best embolic agent characteristics, since it allows for complete occlusion of the aneurysm itself as well as the ability to push the material more distally for occlusion of the residual dysplastic vessel.

Although our patient did not experience significant angiographic vasospasm, this additional element should be considered when discussing de novo aneurysm formation and management of infants with SAH. Other reports have commonly observed angiographic vasospasm in children who present with aneurysm rupture but have rarely noted its clinical significance. ${ }^{10,13,19,21,23,26,38}$ In children younger than 2 years of age, however, vasospasm can be severe, possibly leading to debilitating large-vessel strokes,${ }^{34}$ probably due to high blood vessel reactivity. Reports on the use of nimodipine to reduce the risk of deficit from clinical vasospasm in children with aneurysmal SAH are limited, although its use in adults has been evaluated in the literature. ${ }^{25}$ We safely used nimodipine in the treatment of our patient, suggesting that it is feasible, but the long-term benefit is unknown.

\section{Conclusions}

We present the rare case of a 6-month-old girl who initially presented with a ruptured left MCA aneurysm and returned only 55 days after her initial ictus with de novo aneurysm rupture from an adjacent $\mathrm{M}_{2}$ segment. She was found to be heterozygous for an $M Y H 11$ mutation associated with alterations in vascular smooth muscle structure. To our knowledge, this is the first report of rapid de novo cerebral aneurysm formation in an infant with an $\mathrm{MYH11}$ mutation. Comprehensive review of the literature stresses a high risk of recurrent aneurysm formation and intracranial hemorrhage. Careful imaging surveillance and clinical follow-up is critical to minimize neurological morbidity, especially in infants who present with aneurysm rupture. This case helps us begin to elucidate the long-term effects and consequences of this disease process. Further study of the contribution and impact of the MYH11 mutation is necessary.

\section{References}

1. Agid R, Souza MP, Reintamm G, Armstrong D, Dirks P, Ter-
Brugge KG: The role of endovascular treatment for pediatric aneurysms. Childs Nerv Syst 21:1030-1036, 2005

2. Amendola LM, Dorschner MO, Robertson PD, Salama JS, Hart R, Shirts BH, et al: Actionable exomic incidental findings in 6503 participants: challenges of variant classification. Genome Res 25:305-315, 2015

3. Ashour R, Orbach DB: Interventional neuroradiology in children: diagnostics and therapeutics. Curr Opin Pediatr 27:700-705, 2015

4. Bruneau M, Rynkowski M, Smida-Rynkowska K, Brotchi J, De Witte O, Lubicz B: Long-term follow-up survey reveals a high yield, up to $30 \%$ of patients presenting newly detected aneurysms more than 10 years after ruptured intracranial aneurysms clipping. Neurosurg Rev 34:485-496, 2011

5. Dell S: Asymptomatic cerebral aneurysm: assessment of its risk of rupture. Neurosurgery 10:162-166, 1982

6. Fulkerson DH, Voorhies JM, Payner TD, Leipzig TJ, Horner TG, Redelman K, et al: Middle cerebral artery aneurysms in children: case series and review. J Neurosurg Pediatr 8:79-89, 2011

7. Gerosa M, Licata C, Fiore DL, Iraci G: Intracranial aneurysms of childhood. Childs Brain 6:295-302, 1980

8. Gross BA, Smith ER, Scott RM, Orbach DB: Intracranial aneurysms in the youngest patients: characteristics and treatment challenges. Pediatr Neurosurg 50:18-25, 2015

9. Guo DC, Pannu H, Tran-Fadulu V, Papke CL, Yu RK, Avidan N, et al: Mutations in smooth muscle alpha-actin (ACTA2) lead to thoracic aortic aneurysms and dissections. Nat Genet 39:1488-1493, 2007

10. Heiskanen O, Vilkki J: Intracranial arterial aneurysms in children and adolescents. Acta Neurochir (Wien) 59:55-63, 1981

11. Hetts SW, English JD, Dowd CF, Higashida RT, Scanlon JT, Halbach VV: Pediatric intracranial aneurysms: new and enlarging aneurysms after index aneurysm treatment or observation. AJNR Am J Neuroradiol 32:2017-2022, 2011

12. Hetts SW, Narvid J, Sanai N, Lawton MT, Gupta N, Fullerton HJ, et al: Intracranial aneurysms in childhood: 27-year single-institution experience. AJNR Am J Neuroradiol 30:1315-1324, 2009

13. Huang J, McGirt MJ, Gailloud P, Tamargo RJ: Intracranial aneurysms in the pediatric population: case series and literature review. Surg Neurol 63:424-433, 2005

14. Ikeda DS, Marlin ES, Shaw A, Powers CJ: Successful endovascular reconstruction of a recurrent giant middle cerebral artery aneurysm with multiple telescoping flow diverters in a pediatric patient. Pediatr Neurosurg 50:88-93, 2015

15. Kakarla UK, Beres EJ, Ponce FA, Chang SW, Deshmukh VR, Bambakidis NC, et al: Microsurgical treatment of pediatric intracranial aneurysms: long-term angiographic and clinical outcomes. Neurosurgery 67:237-250, 2010

16. Koroknay-Pál P, Laakso A, Lehto H, Seppä K, Kivisaari R, Hernesniemi J, et al: Long-term excess mortality in pediatric patients with cerebral aneurysms. Stroke 43:2091-2096, 2012

17. Koroknay-Pál P, Lehto H, Niemelä M, Kivisaari R, Hernesniemi J: Long-term outcome of 114 children with cerebral aneurysms. J Neurosurg Pediatr 9:636-645, 2012

18. Koroknay-Pál P, Niemelä M, Lehto H, Kivisaari R, Numminen J, Laakso A, et al: De novo and recurrent aneurysms in pediatric patients with cerebral aneurysms. Stroke 44:14361439,2013

19. Meyer FB, Sundt TM Jr, Fode NC, Morgan MK, Forbes GS, Mellinger JF: Cerebral aneurysms in childhood and adolescence. J Neurosurg 70:420-425, 1989

20. Navarro R, Brown BL, Beier A, Ranalli N, Aldana P, Hanel RA: Flow diversion for complex intracranial aneurysms in young children. J Neurosurg Pediatr 15:276-281, 2015

21. Ostergaard JR, Voldby B: Intracranial arterial aneurysms in children and adolescents. J Neurosurg 58:832-837, 1983 
22. Pannu H, Tran-Fadulu V, Papke CL, Scherer S, Liu Y, Presley C, et al: MYH11 mutations result in a distinct vascular pathology driven by insulin-like growth factor 1 and angiotensin II. Hum Mol Genet 16:2453-2462, 2007

23. Pasqualin A, Mazza C, Cavazzani P, Scienza R, DaPian R: Intracranial aneurysms and subarachnoid hemorrhage in children and adolescents. Childs Nerv Syst 2:185-190, 1986

24. Patel AN, Richardson AE: Ruptured intracranial aneurysms in the first two decades of life. A study of 58 patients. J Neurosurg 35:571-576, 1971

25. Pickard JD, Murray GD, Illingworth R, Shaw MD, Teasdale GM, Foy PM, et al: Effect of oral nimodipine on cerebral infarction and outcome after subarachnoid haemorrhage: British aneurysm nimodipine trial. BMJ 298:636-642, 1989

26. Proust F, Toussaint P, Garniéri J, Hannequin D, Legars D, Houtteville JP, et al: Pediatric cerebral aneurysms. J Neurosurg 94:733-739, 2001

27. Renard M, Callewaert B, Baetens M, Campens L, MacDermot K, Fryns JP, et al: Novel MYH11 and ACTA2 mutations reveal a role for enhanced TGF $\beta$ signaling in FTAAD. Int $\mathbf{J}$ Cardiol 165:314-321, 2013

28. Roche JL, Choux M, Czorny A, Dhellemmes P, Fast M, Frerebeau $\mathrm{P}$, et al: [Intracranial arterial aneurysm in children. A cooperative study. Apropos of 43 cases.] Neurochirurgie 34:243-251, 1988 (Fr)

29. Sanai N, Auguste KI, Lawton MT: Microsurgical management of pediatric intracranial aneurysms. Childs Nerv Syst 26:1319-1327, 2010

30. Sanai N, Quinones-Hinojosa A, Gupta NM, Perry V, Sun PP, Wilson CB, et al: Pediatric intracranial aneurysms: durability of treatment following microsurgical and endovascular management. J Neurosurg 104 (2 Suppl):82-89, 2006

31. Saraf R, Shrivastava M, Siddhartha W, Limaye U: Intracranial pediatric aneurysms: endovascular treatment and its outcome. J Neurosurg Pediatr 10:230-240, 2012

32. Sedzimir CB, Robinson J: Intracranial hemorrhage in children and adolescents. J Neurosurg 38:269-281, 1973

33. Shih P, Pinnaduwage T, Hu LS, Spetzler RF: A pediatric patient with a dissecting thrombotic anterior choroidal artery aneurysm: case report. Neurosurgery 67:E518, 2010

34. Stiefel MF, Heuer GG, Basil AK, Weigele JB, Sutton LN, Hurst RW, et al: Endovascular and surgical treatment of ruptured cerebral aneurysms in pediatric patients. Neurosurgery 63:859-866, 2008

35. Tsutsumi K, Ueki K, Morita A, Usui M, Kirino T: Risk of aneurysm recurrence in patients with clipped cerebral aneurysms: results of long-term follow-up angiography. Stroke 32:1191-1194, 2001

36. van Dijk JM, Groen RJ, Ter Laan M, Jeltema JR, Mooij JJ, Metzemaekers JD: Surgical clipping as the preferred treatment for aneurysms of the middle cerebral artery. Acta Neurochir (Wien) 153:2111-2117, 2011

37. Vargas SA, Diaz C, Herrera DA, Dublin AB: Intracranial aneurysms in children: the role of stenting and flow-diversion. $\mathbf{J}$ Neuroimaging 26:41-45, 2016

38. Weir B: Aneurysms Affecting the Nervous System. Philadelphia: Williams \& Wilkins, 1987

39. Wermer MJ, Greebe P, Algra A, Rinkel GJ: Incidence of recurrent subarachnoid hemorrhage after clipping for ruptured intracranial aneurysms. Stroke 36:2394-2399, 2005

40. Zhu L, Vranckx R, Khau Van Kien P, Lalande A, Boisset N, Mathieu F, et al: Mutations in myosin heavy chain 11 cause a syndrome associating thoracic aortic aneurysm/aortic dissection and patent ductus arteriosus. Nat Genet 38:343-349, 2006

\section{Disclosures}

Dr. Taussky is a consultant for Covidien.

\section{Author Contributions}

Conception and design: Bollo. Acquisition of data: Ravindra, Karsy. Analysis and interpretation of data: Ravindra, Karsy. Drafting the article: Bollo, Ravindra, Karsy. Critically revising the article: all authors. Reviewed submitted version of manuscript: all authors. Approved the final version of the manuscript on behalf of all authors: Bollo. Administrative/technical/material support: Ravindra. Patient care: Karsy, Schmidt, Taussky, Park.

\section{Correspondence}

Robert J. Bollo, Division of Pediatric Neurosurgery, Primary Children's Hospital, 100 North Mario Capecchi Dr., Ste. 1475, Salt Lake City, UT 84113.email: robert.bollo@hsc.utah.edu. 